\title{
Combustion of thermite mixtures based on mechanically alloyed aluminum-iodine material
}

\author{
Sergio E. Guerrero ${ }^{1}$, Edward L. Dreizin ${ }^{2}$, Evgeny Shafirovich ${ }^{1, *}$ \\ ${ }^{1}$ Department of Mechanical Engineering, The University of Texas at El Paso, El Paso, TX 79968 \\ ${ }^{2}$ Department of Chemical, Biological, and Pharmaceutical Engineering, New Jersey Institute of \\ Technology, Newark, NJ 07102 \\ *Corresponding author. Tel.: +1 915747 6465; fax: +1 9157475019. \\ E-mail: eshafirovich2@utep.edu (E. Shafirovich).
}

Brief Communication

\begin{abstract}
Halogen-containing reactive materials could be used for mitigating the spread of hazardous, active biological microorganisms aerosolized as a result of explosion. Here we present experimental results on combustion of mechanically alloyed aluminum-iodine $\left(\mathrm{Al} \cdot \mathrm{I}_{2}\right)$ powder mixed with $\mathrm{Fe}_{2} \mathrm{O}_{3}, \mathrm{CuO}, \mathrm{MoO}_{3}, \mathrm{Bi}_{2} \mathrm{O}_{3}$, and $\mathrm{I}_{2} \mathrm{O}_{5}$. The mixtures were compacted into pellets and ignited with a $\mathrm{CO}_{2}$ laser. High-speed video recording was used for observations. Mixtures of the $\mathrm{Al} \cdot \mathrm{I}_{2}$ powder with $\mathrm{Fe}_{2} \mathrm{O}_{3}$ did not ignite, while mixtures of this powder with the other oxides exhibited a self-sustained propagation of the combustion front with similar burn rates. Comparison experiments with a finer, micron-sized Al powder have shown a more rapid combustion of mixtures based on metal oxides and, in contrast, a slower and unsteady combustion of $\mathrm{Al} / \mathrm{I}_{2} \mathrm{O}_{5}$ thermite. These observations are interpreted based on the analysis of reaction mechanisms.
\end{abstract}

Keywords: Heterogeneous combustion; Thermites; Biocidal reactive materials; Laser ignition 


\section{Introduction}

Halogen-containing reactive materials could be used for mitigating the spread of hazardous, active biological microorganisms aerosolized as a result of explosion [1, 2]. Different methods for incorporating halogens in reactive materials have been considered. In particular, reactive compositions including halogen-containing thermites have been explored [3-7]. The tested mixtures included metal powders and halogen-containing oxides such as iodine pentoxide $\left(\mathrm{I}_{2} \mathrm{O}_{5}\right)$ and silver iodate $\left(\mathrm{AgIO}_{3}\right)$.

Recently, a mechanically alloyed aluminum-iodine $\left(\mathrm{Al} \cdot \mathrm{I}_{2}\right)$ powder has been synthesized [8]. Relatively low ignition temperatures of this powder $[9,10]$ imply that it can substitute aluminum in thermite mixtures, thus serving as a fuel and, at the same time, the source of iodine. It is expected that the use of this material instead of aluminum in thermite mixtures based on iodinecontaining oxides would increase iodine yield, while maintaining the mixture's high energy density. Further, thermite mixtures of $\mathrm{Al} \cdot \mathrm{I}_{2}$ powder with oxides of metals such as iron, copper, bismuth, and molybdenum could be used for iodine generation when relatively small amounts of iodine are sufficient and the use of unstable and hygroscopic iodine-containing oxides is not desired.

The objective of present paper is to investigate combustion of thermite mixtures that include the mechanically alloyed $\mathrm{Al} \cdot \mathrm{I}_{2}$ powder and the following oxides: $\mathrm{Fe}_{2} \mathrm{O}_{3}, \mathrm{CuO}, \mathrm{MoO}_{3}, \mathrm{Bi}_{2} \mathrm{O}_{3}$, and $\mathrm{I}_{2} \mathrm{O}_{5}$. It was also desired to compare combustion characteristics of these mixtures with those of thermites based on commercial, micron-sized Al powder.

\section{Experimental}

Mechanically alloyed $\mathrm{Al} \cdot \mathrm{I}_{2}\left(20 \mathrm{wt} \% \mathrm{I}_{2}\right)$ powder was fabricated by ball milling at the liquid nitrogen temperature. Details are given elsewhere [8]. A commercially available aluminum powder (97.5\% pure, spherical, Alfa Aesar) was used in experiments conducted for comparison. Bismuth (III) oxide $\left(\mathrm{Bi}_{2} \mathrm{O}_{3}, 99.9 \%\right.$ pure), copper (II) oxide (CuO, >99.0\% pure), and molybdenum (VI) oxide $\left(\mathrm{MoO}_{3}, 99.5 \%\right.$ pure) were obtained from Alfa Aesar, while iron (III) oxide $\left(\mathrm{Fe}_{2} \mathrm{O}_{3},>99 \%\right.$ pure $)$ and iodine pentoxide $\left(\mathrm{I}_{2} \mathrm{O}_{5}, 98 \%\right.$ pure $)$ were supplied by Sigma Aldrich.

Particle size distributions of the used powders were determined using a multi-laser particle size analyzer (Microtrac Bluewave) with isopropyl alcohol as the carrier liquid.

Both $\mathrm{Al}$ and $\mathrm{Al} \cdot \mathrm{I}_{2}$ powders were mixed with the oxides according to the stoichiometries of Al-oxygen reactions, i.e., $\mathrm{I}_{2}$ was considered as an inert additive. The mixing was conducted in an acoustic mixer (Resodyne LabRAM) with an intensity of $40 \%$ for 2 min. Wet (hexane) mixing was used. The mixtures were compressed into pellets (diameter $6 \mathrm{~mm}$, height 6-14 $\mathrm{mm}$ ) using a uniaxial hydraulic press (force 9.8-14.7 kN).

The pellets were ignited by an infrared (wavelength $10.6 \mu \mathrm{m}$ ) beam of a $\mathrm{CO}_{2}$ laser (Synrad Firestar ti-60). The experiments were conducted in air at atmospheric pressure. Figure 1 shows the experimental setup. A sealed aluminum chamber (inner diameter $70 \mathrm{~mm}$, length $160 \mathrm{~mm}$ ) is equipped with two removable window ports and a zinc selenide ( $\mathrm{ZnSe}$ ) window. The pellet is installed vertically on a brass pedestal. The laser beam enters the chamber through the $\mathrm{ZnSe}$ window and heats the pellet at the top. To prevent damage by high-temperature combustion products, the $\mathrm{ZnSe}$ window is installed at the top end of a long $(30 \mathrm{~cm})$ vertical tube. The beam diameter at the pellet top is about $3 \mathrm{~mm}$. The pellet is aligned with the infrared beam using a diode pointer (Synrad), which emits a visible red laser beam aligned with the $\mathrm{CO}_{2}$ laser beam. 
The power of the $\mathrm{CO}_{2}$ laser beam is controlled by a laser controller (Synrad UC-2000). In the reported experiments, the actual power of the beam after passing the beam delivery system and ZnSe window, measured with a powermeter (Synrad PW-250), was 58-60 W. The duration of the laser pulse is set using LabVIEW (National Instruments) software connected to the laser controller. A custom-made electronic scheme based on a photoresistor turns off the laser pulse upon the ignition. A high-speed video camera (Vision Research Phantom v1210), equipped with a lens for macro shooting (Nikon AF Micro NIKKOR 60mm f/2.8D), is used for observations of the combustion process and measurements of the front velocity. In the present research, the resolution was $1024 \times 768$ and the frame rate was varied from 1000 to $7000 \mathrm{fps}$.

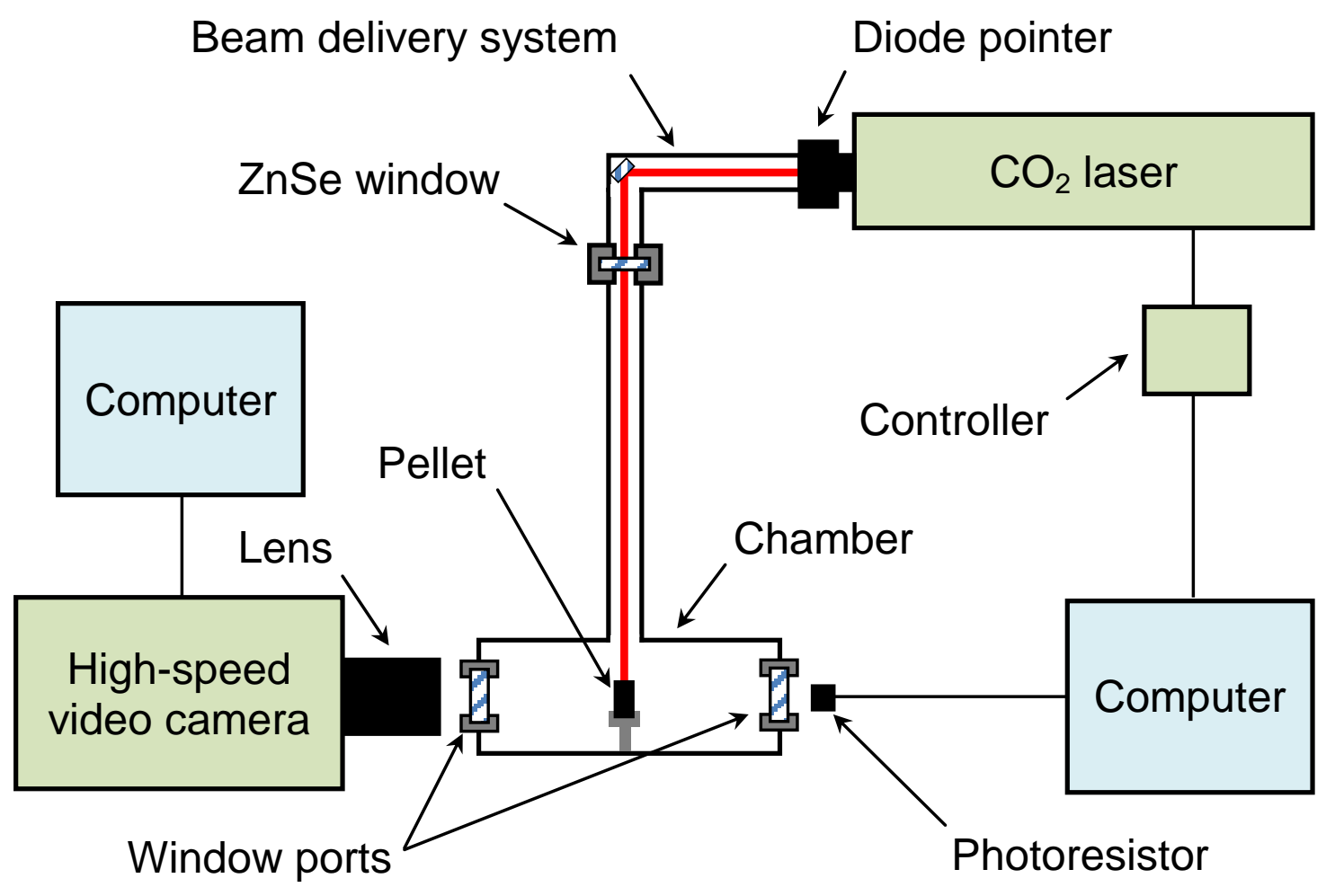

Fig 1. Experimental setup. 


\section{Results}

Table 1 describes particle size distributions measured for the used fuels and oxidizers. Included are the mean volume diameter $d_{m v}$, the median diameter $d_{50}$, and parameters $d_{10}$ and $d_{90}$ (the complete particle size distributions are included in the Supplementary material). It is seen that mechanically alloyed $\mathrm{Al} \cdot \mathrm{I}_{2}$ powder is coarser than the commercial Al powder, which is characterized by a mean volume diameter of about $8 \mu \mathrm{m}$. The $\mathrm{Al} \cdot \mathrm{I}_{2}$ powder and oxides of $\mathrm{Cu}$ and Mo have similar distributions. The mean volume diameters of these three powders are in the range from 20 to $30 \mu \mathrm{m}$. Oxides of bismuth and iron are finer (the mean volume diameter is 4 $\mu \mathrm{m}$ for the former and $10 \mu \mathrm{m}$ for the latter). Iodine pentoxide is the coarsest powder, with the mean volume diameter of about $70 \mu \mathrm{m}$.

Table 1. Particle size distribution parameters of the used fuels and oxidizers.

\begin{tabular}{|c|c|c|c|c|}
\hline & $\boldsymbol{d}_{\boldsymbol{m} \boldsymbol{v}}, \boldsymbol{\mu m}$ & $\boldsymbol{d}_{\mathbf{1 0}}, \boldsymbol{\mu m}$ & $\boldsymbol{d}_{\mathbf{5 0}, \boldsymbol{\mu m}}$ & $\boldsymbol{d}_{\mathbf{9 0}, \boldsymbol{\mu m}}$ \\
\hline $\mathbf{A l}$ & 7.70 & 3.62 & 7.15 & 12.57 \\
\hline $\mathbf{A l} \cdot \mathbf{I}_{\mathbf{2}}$ & 19.76 & 5.09 & 16.08 & 40.34 \\
\hline $\mathbf{C u O}$ & 28.07 & 7.09 & 23.60 & 53.23 \\
\hline $\mathbf{M o O} \mathbf{O}_{\mathbf{3}}$ & 22.58 & 7.99 & 17.90 & 40.27 \\
\hline $\mathbf{B i}_{\mathbf{2}} \mathbf{O}_{\mathbf{3}}$ & 4.24 & 1.148 & 2.621 & 8.69 \\
\hline $\mathbf{F e}_{\mathbf{2}} \mathbf{O}_{\mathbf{3}}$ & 10.24 & 1.264 & 2.265 & 31.84 \\
\hline $\mathbf{I}_{\mathbf{2}} \mathbf{O}_{\mathbf{5}}$ & 69.90 & 4.85 & 47.53 & 168.9 \\
\hline
\end{tabular}

Several experiments were conducted with each mixture. Typical videos obtained for mixtures based on mechanically alloyed $\mathrm{Al} \cdot \mathrm{I}_{2}$ powder are included in the Supplementary material, while Figure 2 shows still images from these videos.

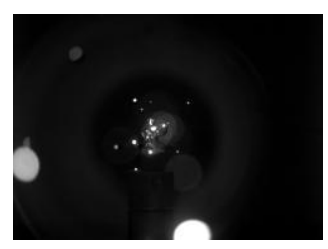

(a)

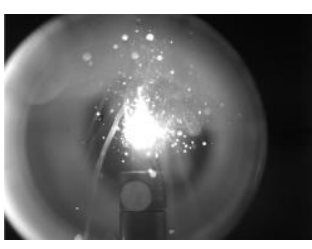

(b)

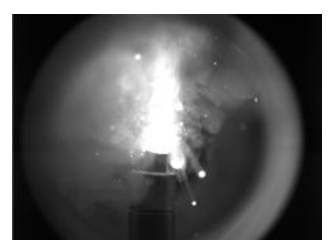

(c)

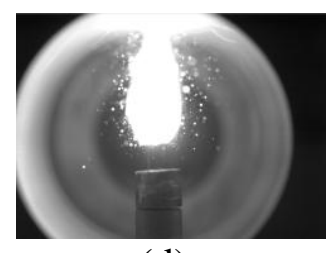

(d)

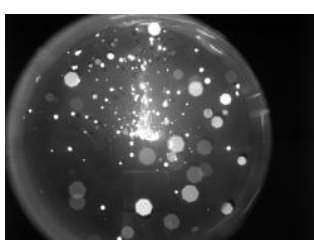

(e)

Fig. 2. Still Frames from High Speed Videos. These still frames from high speed videos (frame rate: 1000 fps), included in the Supplementary material, show mixtures of mechanically alloyed $\mathrm{Al} \cdot \mathrm{I}_{2}$ powder with (a) $\mathrm{Fe}_{2} \mathrm{O}_{3}$, (b) $\mathrm{MoO}_{3}$, (c) $\mathrm{Bi}_{2} \mathrm{O}_{3}$, (d) $\mathrm{CuO}$, and (e) $\mathrm{I}_{2} \mathrm{O}_{5}$. The image for iron oxide based mixture is taken from the laser heating phase of the process because this mixture did not ignite. The images for other mixtures are taken from the combustion propagation phase. 
Table 2 shows the relative densities of the mixtures and the measured velocities of combustion front propagation. No reliable conclusions were made based on the ignition delays because they varied in the range of $0.01-0.4 \mathrm{~s}$, apparently because of variation of the pellet absorptivity.

Table 2. Characteristics of studied thermite mixtures.

\begin{tabular}{|c|c|c|c|c|}
\hline \multirow{2}{*}{ Oxidizer } & \multicolumn{2}{|c|}{$\mathbf{A l} \cdot \mathbf{I}_{\mathbf{2}}$} & \multicolumn{2}{c|}{ Al } \\
\cline { 2 - 5 } & $\begin{array}{c}\text { Relative density, } \\
\mathbf{\%}\end{array}$ & $\begin{array}{c}\text { Front velocity, } \\
\mathbf{m m} / \mathbf{s}\end{array}$ & $\begin{array}{c}\text { Relative density, } \\
\mathbf{\%}\end{array}$ & $\begin{array}{c}\text { Front velocity, } \\
\mathbf{m m} / \mathbf{s}\end{array}$ \\
\hline $\mathbf{F e}_{\mathbf{2}} \mathbf{O}_{\mathbf{3}}$ & $59-83$ & No ignition & No test & No test \\
\hline $\mathbf{M o O}_{\mathbf{3}}$ & $66-74$ & 6 & $71-72$ & $>100$ \\
\hline $\mathbf{B i}_{\mathbf{2}} \mathbf{O}_{\mathbf{3}}$ & $71-76$ & 10 & $71-77$ & $>100$ \\
\hline $\mathbf{C u O}_{\mathbf{n y y y y}}$ & $66-85$ & $13-18$ & $72-74$ & $>100$ \\
\hline $\mathbf{I}_{\mathbf{2}} \mathbf{O}_{\mathbf{5}}$ & $84-86$ & $13-16$ & $73-90$ & $\sim 5$ \\
\hline
\end{tabular}

The mixtures of Al- $\mathrm{I}_{2}$ and $\mathrm{Fe}_{2} \mathrm{O}_{3}$ powders did not ignite. The luminous zone created by laser heating did not expand, i.e., the reaction did not propagate. The only effect of laser heating was ejection of fragments and gradual destruction of the pellet (Fig. 2-a).

The mixtures of $\mathrm{Al} \cdot \mathrm{I}_{2}$ with $\mathrm{MoO}_{3}, \mathrm{Bi}_{2} \mathrm{O}_{3}$, and $\mathrm{CuO}$ powders ignited and burned in a selfsustained manner with average front velocities varied in the range of $6-18 \mathrm{~mm} / \mathrm{s}$. The lowest velocity and unsteady phenomena were observed during combustion $\mathrm{Al} \cdot \mathrm{I}_{2} / \mathrm{MoO}_{3}$ mixtures (Fig. 2-b), while those based on $\mathrm{Bi}_{2} \mathrm{O}_{3}$ and $\mathrm{CuO}$ exhibited a steady front propagation (Figs. 2-c and 2d).

The mixtures of $\mathrm{Al} \cdot \mathrm{I}_{2}$ and $\mathrm{I}_{2} \mathrm{O}_{5}$ powders also burned steadily with a front velocity of 13-16 $\mathrm{mm} / \mathrm{s}$, but the combustion zone looks different compared to other thermite systems (Fig. 2-e). Instead of a uniform luminous zone, the combustion front consists of numerous hot spots, separated from each other. It is seen how the incandescent fragments are ejected from the pellet, leading to the full dispersion of the material.

In the comparison experiments with mixtures based on commercial $\mathrm{Al}$ powder and the same metal oxides $\left(\mathrm{MoO}_{3}, \mathrm{Bi}_{2} \mathrm{O}_{3}\right.$, and $\left.\mathrm{CuO}\right)$, a much faster combustion was observed: the front velocities exceeded $100 \mathrm{~mm} / \mathrm{s}$. In contrast, combustion of the mixture of $\mathrm{Al}$ and $\mathrm{I}_{2} \mathrm{O}_{5}$ powders was relatively slow (ca. $5 \mathrm{~mm} / \mathrm{s}$ ) and unsteady.

\section{Discussion}

The experiments have shown that the front velocities in all mixtures with $\mathrm{Al} \cdot \mathrm{I}_{2}$ powder are similar to one another, despite different chemical compositions and particle sizes of the oxidizers tested. This indicates that the reaction may be controlled by the processes related to the metal particles. Prior studies [11] have shown that low-temperature oxidation of Al particles is controlled by outward diffusion of $\mathrm{Al}$ ions to the exterior of the oxide shell covering the metal. It is possible that this process also controls the reaction between $\mathrm{Al} \cdot \mathrm{I}_{2}$ and metal oxide particles during propagation of the combustion wave over their mixture. 
Further, the experiments have shown that the front velocities in the mixtures with $\mathrm{Al} \cdot \mathrm{I}_{2}$ powder and metal oxides are much lower than those for the mixtures of the same oxides with a commercial, micron-sized $\mathrm{Al}$ powder. To verify that this effect is not caused by the decrease in the combustion temperature due to the addition of iodine, the adiabatic flame temperatures of all studied mixtures were calculated for 1 atm pressure using THERMO software [12]. The formation enthalpy of $\mathrm{I}_{2} \mathrm{O}_{5},-157.92 \mathrm{~kJ} / \mathrm{mol}$ [13], was added to the database. It was assumed in the calculations that $\mathrm{Al} \cdot \mathrm{I}_{2}$ material is just a mixture of $\mathrm{Al}$ and $\mathrm{I}_{2}$. The results have shown that the replacement of $\mathrm{Al}$ with $\mathrm{Al} \cdot \mathrm{I}_{2}$ decreases the adiabatic flame temperature of all mixtures by 11-80 $\mathrm{K}$ (the obtained values are in the range $2800-3800 \mathrm{~K}$ and are included in the Supplementary material). Such a small reduction in the temperature cannot explain the significant decreases in the velocity of front propagation observed for thermites based on metal oxides.

The decrease in the front velocity may be associated with a larger size of mechanically alloyed $\mathrm{Al} \cdot \mathrm{I}_{2}$ powder (see Table 1 ). In a recent study on the ignition mechanisms of thermites [14], the investigated mixtures included nanoscale Al and different metal oxides including the four oxides studied in the present paper. It was shown that at least for thermites based on $\mathrm{Bi}_{2} \mathrm{O}_{3}$, $\mathrm{MoO}_{3}, \mathrm{SnO}_{2}, \mathrm{Sb}_{2} \mathrm{O}_{3}$, and $\mathrm{WO}_{3}$, the ignition is likely a result of direct interfacial contact between fuel and oxidizer, leading to condensed state mobility of reactive species, rather than a result of reaction with gaseous oxygen released from the metal oxides. Apparently, the same mechanism takes place during ignition of all thermites studied in the present work, except for $\mathrm{I}_{2} \mathrm{O}_{5}$-based mixture. Since $\mathrm{Al} \cdot \mathrm{I}_{2}$ powder is coarser than the tested Al powder, it has a lower area of contact with the oxide, which decelerates the reaction between the metal and oxide particles. The nonignition of $\mathrm{Al} \cdot \mathrm{I}_{2} / \mathrm{Fe}_{2} \mathrm{O}_{3}$ mixtures correlates with the high ignition temperature of $\mathrm{Al} / \mathrm{Fe}_{2} \mathrm{O}_{3}$ thermite as compared with those of other aluminum - metal oxide thermites [14].

The mechanism of oxygen transport to metal particles during combustion of $\mathrm{I}_{2} \mathrm{O}_{5}$-based thermites is probably different. It is known that iodine pentoxide decomposes to $\mathrm{O}_{2}$ and $\mathrm{I}_{2}$ at a relatively low temperature of about $400{ }^{\circ} \mathrm{C}$ [4]. Thus, it is likely that the reaction does not happen at the particle-particle interface, but rather in the gas phase. It has been observed earlier that at such temperatures, mechanically alloyed $\mathrm{Al} \cdot \mathrm{I}_{2}$ powder rapidly reacts with gaseous oxygen $[9,10]$. Combustion of the $\mathrm{Al} \cdot \mathrm{I}_{2} / \mathrm{I}_{2} \mathrm{O}_{5}$ mixtures may still depend on the outward diffusion of $\mathrm{Al}$ through the particle oxide shells, but the observed different structure of the combustion front (hot spots rather than a uniform luminous zone) supports the hypothesis of a different combustion mechanism.

These considerations also explain the observed slow and unsteady combustion of $\mathrm{Al} / \mathrm{I}_{2} \mathrm{O}_{5}$ thermite. Indeed, oxidation of conventional micron-sized Al powders begins at a higher temperature than for the mechanically alloyed $\mathrm{Al} \cdot \mathrm{I}_{2}$ powder. The temperature at which significant oxidation of $\mathrm{Al}$ begins, $\mathrm{I}_{2} \mathrm{O}_{5}$ is already expected to decompose. Thus, in the prepared powder mixtures, the zones of $\mathrm{I}_{2} \mathrm{O}_{5}$ decomposition and $\mathrm{Al}$ oxidation in the combustion wave may be spatially separated, causing a decrease in the front velocity.

\section{Conclusions}

Mixtures of the mechanically alloyed $\mathrm{Al} \cdot \mathrm{I}_{2}$ powder with $\mathrm{Fe}_{2} \mathrm{O}_{3}$ do not ignite. Mixtures of the same powder with other oxides exhibit a self-sustained propagation of the combustion front with similar burn rates. Comparison experiments with a finer, micron-sized Al powder have shown a more rapid combustion for mixtures based on metal oxides. In contrast, a slower and unsteady combustion was observed for $\mathrm{Al} / \mathrm{I}_{2} \mathrm{O}_{5}$ thermite. 
Similar burn rates for thermites with $\mathrm{Al} \cdot \mathrm{I}_{2}$ mixed with different oxides indicate that the reaction is controlled by outward Al diffusion through the oxide shells of metal particles. In mixtures with metal oxides, the reaction requires interfacial contact between the fuel and oxidizer, so that replacing $\mathrm{Al} \cdot \mathrm{I}_{2}$ with a finer $\mathrm{Al}$ powder increases the reaction rate. In contrast, in mixtures with iodine pentoxide, aluminum reacts with gaseous oxygen released by the oxide decomposing at a lower temperature. Since oxidation of $\mathrm{Al} \cdot \mathrm{I}_{2}$ and decomposition of $\mathrm{I}_{2} \mathrm{O}_{5}$ occur in the same temperature range, $\mathrm{Al} \cdot \mathrm{I}_{2} / \mathrm{I}_{2} \mathrm{O}_{5}$ mixtures burn rapidly. In contrast, $\mathrm{Al} / \mathrm{I}_{2} \mathrm{O}_{5}$ mixtures exhibit a slow and unsteady combustion because the oxidation temperatures of the micron-sized $\mathrm{Al}$ powder are higher than the decomposition temperature of $\mathrm{I}_{2} \mathrm{O}_{5}$.

\section{Acknowledgments}

This research was supported by the U.S. Department of Defense (Grants No. W911NF-12-10056 and No. W911NF-14-1-0034; Grant Officer's Representative: Dr. Ralph A. Anthenien of the Army Research Office; Co-GOR: Dr. Clifford D. Bedford of the Office of Naval Research).

\section{References}

[1] S.A. Grinshpun, C. Li, A. Adhikari, M. Yermakov, T. Reponen, M. Schoenitz, E. Dreizin, V. Hoffman, M. Trunov, Method for studying survival of airborne viable microorganisms in combustion environments: Development and evaluation, Aerosol Air Qual. Res. 10 (2010) 414-424.

[2] Y. Aly, S. Zhang, M. Schoenitz, V.K. Hoffmann, E.L. Dreizin, M. Yermakov, R. Indugula, S.A. Grinshpun, Iodine-containing aluminum-based fuels for inactivation of bioaerosols, Combust. Flame 161 (2014) 303-310.

[3] B.R. Clark, M.L. Pantoya, The aluminium and iodine pentoxide reaction for the destruction of spore forming bacteria, Phys. Chem. Chem. Phys. 12 (2010) 12653-12657.

[4] C. Farley, M. Pantoya, Reaction kinetics of nanometric aluminum and iodine pentoxide, J. Therm. Anal. Calorim. 102 (2010) 609-613.

[5] R. Russell, S. Bless, M. Pantoya, Impact-driven thermite reactions with iodine pentoxide and silver oxide, J. Energy Mater. 29 (2011) 175-192.

[6] K.T. Sullivan, N.W. Piekiel, S. Chowdhury, C. Wu, M.R. Zachariah, C.E. Johnson, Ignition and combustion characteristics of nanoscale $\mathrm{Al} / \mathrm{AgIO}_{3}$ : a potential energetic biocidal system, Combust. Sci. Technol. 183 (2011) 285-302.

[7] C.E. Johnson, K.T. Higa, Iodine-rich biocidal reactive materials, MRS Online Proc. Libr. 1521 (2013), DOI: 10.1557/opl.2013.46.

[8] S. Zhang, M. Schoenitz, E.L. Dreizin, Mechanically alloyed Al-I composite materials, J. Phys. Chem. Solids 71 (2010) 1213-1220.

[9] S. Zhang, M. Schoenitz, E.L. Dreizin, Iodine release, oxidation, and ignition of mechanically alloyed Al-I composites, J. Phys. Chem. C 114 (2010) 19653-19659.

[10] S. Zhang, C. Badiola, M. Schoenitz, E.L. Dreizin, Oxidation, ignition, and combustion of Al- $\mathrm{I}_{2}$ composite powders, Combust. Flame 159 (2012) 1980-1986.

[11] S. Zhang, E.L. Dreizin, Reaction interface for heterogeneous oxidation of aluminum powders, J. Phys. Chem. C, 117 (2013) 14025-14031.

[12] A.A. Shiryaev, Thermodynamics of SHS processes: An advanced approach, Int. J. SHS 4 (1995) 351-362.

[13] M.W. Chase, NIST-JANAF thermochemical tables for the iodine oxides, J. Phys. Chem. Ref. Data 25 (1996) 1297-1340. 
[14] G. Jian, S. Chowdhury, K. Sullivan, M.R. Zachariah, Nanothermite reactions: Is gas phase oxygen generation from the oxygen carrier an essential prerequisite to ignition? Combust. Flame 160 (2013) 432-437. 